\title{
The functional role of one-word mediators
}

\author{
FRANCIS S. BELLEZZA \\ Ohio University, Athens, Ohio 45701 \\ ALEX J. POPLAWSKY \\ Bloomsburg State College, Bloomsburg, Pennsylvania 17815 \\ and \\ LINDA A. ARONOVSKY \\ Ohio University, Athens, Ohio 45701
}

\begin{abstract}
An experiment was performed to demonstrate that natural language mediators are not merely associations to word pairs, but also play a role in learning by reducing the learning of a pairedassociate item to two simpler learning tasks. Although the study times were the same, subjects who gave one word as an association to each word pair performed more poorly on measures of retention than did subjects who gave one word which described or connected the two words of each pair. Also, evidence for some independent visual-image mediation was found.
\end{abstract}

When subjects are given a paired-associate learning task in which the items have nonlanguage components such as CVCs, the learning of each item is often accompanied by a natural language mediator (Bugelski, 1962; Montague, Adams, \& Kiess, 1966; Underwood \& Schulz, 1960). The natural language mediator is usually a word or phrase that sounds like or, when written, looks like the original item but is part of the subject's natural language. It has been found that the presence of a natural language mediator for an item indicates that the subject is more likely to have learned and is more likely to retain that item compared to an item for which no natural language mediator has been reported (for a review see Montague, 1972). Although interesting phenomena in their own right, natural language mediators may also provide an index by which the depth of processing (Craik \& Lockhart, 1972) or degree of elaboration (Craik \& Tulving, 1975) can be measured.

Bellezza and Poplawsky (1974) found that natural language mediators facilitated learning even when the pairs being learned were randomly paired nouns which were already part of the subjects' natural language. For some of the presented pairs the subjects were asked to give one word that described, connected, or associated the two words in the pair. They found that pairs for which a one-word mediator was requested were recalled significantly better than control pairs which the subjects were told to silently study. Also, as found in other studies such as Montague et al. (1966), the response

This research was supported in part by a grant from the Field-Wiltsie Foundation and by a grant from the Ohio University Research Committee. The authors would like to thank Ohio University Computer Services for making computer time available. Requests for reprints should be sent to Francis S. Bellezza, Department of Psychology, Ohio University, Athens, Ohio 45701. word was almost never recalled unless the mediator word was also recalled.

There is agreement resulting from experimentation that if the subject can give a natural language mediator during study and also recall the natural language mediator during the test of the item, then there is a high probability that the response will also be given. However, there is disagreement as to whether or not the natural language mediator plays any functional role in learning. The mediator could be merely an epiphenomenon which accompanies learning but reflects no process involved in the actual learning of the pair (Adams \& McIntyre, 1967; Underwood, 1972). This criticism can be made of almost any study utilizing natural language mediation. Bellezza and Poplawsky (1974) discussed the possibility that the one-word mediator given for a word pair in their experiment may not have been a mediating link between the two presented words, but merely a strong associate to one or both of the words in the pair. The result that the mediated pairs were recalled better could be caused by the subject perceiving the word pairs requiring a mediator as being more important than the control pairs. Consequently, they would be rehearsed more.

The two hypotheses and their underlying assumptions can be stated as follows.

Association hypothesis. When the subject is presented with a word pair, he generates a strong associate to either one of the words, or both, and then proceeds to learn the stimulus-response pair. If a mediator is not given during the study period, then it cannot be expected that the response will be learned (Montague et al., 1966). This can be explained by assuming that any pair that is not meaningful enough to the subject to generate some natural language association is not going to be meaningful enough to be easily learned. The 
natural language mediator is then a test of the meaningfulness of the pair (Underwood \& Schulz, 1960). If the subject can remember the response during the testing of the item, he will probably be able to generate the high associate given to the pair during its presentation. It is also assumed that responding with a strong-associate word to the presented pair is a relatively rapid response.

Mediation hypothesis. This could also be called the problem-solving hypothesis because the subject is faced with the problem of discovering a mediating word that connects the two presented words (Reed, 1918). This must be done in such a way that the two links combined, one between the stimulus and the mediator word and one between the mediator word and the response, are easier to remember than the original association between the stimulus and the response words (Bellezza \& Poplawsky, 1974). What is assumed here is that some word-pair combinations are easier to remember than others, and that the subject's task is to find a word in his semantic memory that will transform the original task into two easy tasks. It is also assumed that finding a good connecting word is a trial-and-error procedure in memory search and is relatively time consuming.

The two hypotheses were tested by instructing one group of subjects to quickly give a strong associate to the word pair and then to study the pair (the association group). The subjects in the mediation group were instructed to use as much of the study time as possible to find a mediator word that would meaningfully connect the two presented words. In order to make the results more general than those of Bellezza and Poplawsky (1974), who used only concrete nouns, both abstract and concrete noun pairs were used.

\section{METHOD}

\section{Subjects}

Sixty-four students from introductory psychology courses at Ohio University volunteered for course credit.

\section{Materials \\ Twenty-four pairs of words were made up using the Paivio, Yuille, and Madigan (1968) norms. Half the pairs were made up of abstract words (imagery rating of less than 2.77) and the other half were made up of concrete words (imagery rating of more than 6.60). The pairs were constructed so that the words in each pair bore no obvious relation to one another. Examples of the two types of pairs are "concept-soul" and "kiss-sunset." Using the same words, two different sets of pairs were made up. In addition, two different presentation and test randomizations were used for each set of pairs. Therefore, there were four sets of experimental materials.}

\section{Procedure}

The subjects were tested individually using a Lafayette IBM memory drum and were randomly assigned to a condition when they arrived for the experiment. Each subject was presented each word pair for $20 \mathrm{sec}$ and was asked to say the words aloud when they appeared. The 32 subjects in the association group were instructed to vocally add to the presented pair the first word that came to mind and then to take the rest of the $20 \mathrm{sec}$ to try to memorize and associate all three words. The 32 subjects in the mediation group were instructed to study the words for up to $20 \mathrm{sec}$ and then to vocally add a third word that associated, connected, or described the two presented words.

The 24 pairs were presented for two trials using a study-test procedure and were presented and tested in a different order on each trial. The subjects were instructed to try to use the same added word for each pair on both trials. Eight subjects from each group were tested with each set of experimental materials. After each presentation, the experimenter vocally presented each of the stimulus words from the list and the subject was given $20 \mathrm{sec}$ to respond with both the added word and the response word. The first three pairs tested were selected from the first half of the presentation list to avoid responding from short-term store.

The main part of the experiment was preceded by a 12-item practice list made up of six abstract and six concrete word pairs which were presented and tested only once.

\section{Analysis}

A 2 by 2 by 2 analysis of variance was performed on the data, with the factors being strategy group (association vs. mediation), pair imagery (abstract vs. concrete), and trials. Both pair imagery and trials were within-subjects factors. The analysis was performed on four dependent variables: (1) the proportion of response words recalled, (2) the proportion of added words recalled, which consisted of either associations or mediations, (3) the proportion of response words recalled given that the added word had been recalled, and (4) the proportion of response words recalled given that the added word had not been recalled. All tests of significance were performed with alpha set to .05 .

\section{RESULTS}

In general, the subjects were able to follow the instructions. On the first trial almost all the added words from the association group were given during the first $5 \mathrm{sec}$ of the presentation of each pair; in the mediation group almost all the added words were given $10-20 \mathrm{sec}$ after the pair was presented. On the second trial subjects in the mediation group tended to respond more quickly than they did on the first trial because they remembered the added word for some of the pairs.

The proportion of correct responses, $\mathrm{P}(\mathrm{R})$, for each type of pair for each group is shown in Table 1. The strategy group factor was significant $[F(1,62)=17.01$,

Table 1

Proportion of Response Words Recalled in the Different Experimental Conditions

\begin{tabular}{lcccccccc}
\hline Condi- & \multicolumn{2}{c}{$P(R)$} & \multicolumn{3}{c}{$P(A)$} & \multicolumn{2}{c}{$P(R \mid A)$} & \multicolumn{2}{c}{$P(R \mid$ no A) } \\
tion & $T_{1}$ & $T_{2}$ & $T_{1}$ & $T_{2}$ & $T_{1}$ & $T_{2}$ & $T_{1}$ & $T_{2}$ \\
\hline & \multicolumn{8}{c}{ Association Group } \\
Abstract & .17 & .30 & .41 & .58 & .29 & .45 & .06 & .06 \\
Concrete & .51 & .77 & .72 & .90 & .63 & .81 & .10 & .18 \\
& \multicolumn{8}{c}{ Mediation Group } \\
Abstract & .22 & .47 & .43 & .63 & .42 & .65 & .08 & .17 \\
Concrete & .79 & .95 & .86 & .96 & .88 & .97 & .24 & .17 \\
\hline
\end{tabular}

Note $-P(R)=$ proportion of correct responses recalled, $P(A)=$ proportion of correct added words recalled, $P(R \mid A)=$ proportion of responses recalled given that the added word was recalled, $P(R \mid$ no $A)=$ proportion of responses recalled given that the added word was not recalled, $T_{1}=$ Trial $1, T_{2}=$ Trial 2. 
MSe $=.106]$, as was pair imagery $[F(1,62)=417.56$, $\mathrm{MSe}=.033]$ and trials $[\mathrm{F}(1,62)=293.57, \mathrm{MSe}=.009]$. Two interactions were also significant: Strategy Group by Pair Imagery $[\mathrm{F}(1,62)=7.49, \mathrm{MSe}=.033]$ and Strategy Group by Pair Imagery by Trials $[F(1,62)=$ $11.89, \mathrm{MSe}=.016]$. As can be seen from the data presented in Table 1, the two-way interaction occurred because the concrete pairs in the mediation group showed the highest level of performance. The three-way interaction was caused by the result that the abstract pairs in the association group were learned at a rate slower than the concrete pairs in the association group or either type of pair in the mediation group. A Cicchetti (1972) test modified for a mixed design showed that the only two proportions of response words recalled not significantly different were the performance levels on the abstract pairs for the association and mediation groups on Trial 1.

The analysis of variance on the proportion of added words recalled, $\mathrm{P}(\mathrm{A})$, showed strategy group to be significant $[\mathrm{F}(1,62)=4.49, \mathrm{MSe}=.068]$, as well as pair imagery $[\mathrm{F}(1,62)=276.24, \mathrm{MSe}=.028]$ and trials $[\mathrm{F}(1,62)=124.48, \mathrm{MSe}=.012]$. As can be seen from Table 1 , the association group recalled significantly fewer added words than did the mediation group. Also, more added words were recalled for the concrete than for the abstract pairs.

Next analyzed was the proportion of correct responses given that the correct added word had also been recalled, $P(R \mid A)$. The pattern of significance was much the same as that for the recall of the added words. Strategy group was significant $[\mathrm{F}(1,62)=14.47, \mathrm{MSe}=$ $.147]$, as was pair imagery $[\mathrm{F}(1,62)=1.55 .28$, MSe $=$ .057] and trials $[\mathrm{F}(1,62)=90.08$, MSe $=.019]$. The resulting proportions are shown in Table 1 .

Finally, when the proportion of correct responses given that the correct added word was not recalled, $\mathrm{P}(\mathrm{R}$ Ino $\mathrm{A})$, was analyzed, only pair imagery was significant $[\mathrm{F}(1,62)=9.83, \mathrm{MSe}=.041]$. The data in Table 1 show that responses were correctly recalled without added words at a rate higher for concrete pairs than for abstract pairs. This was true regardless of the learning strategy used.

\section{DISCUSSION}

The results support the hypothesis that natural language mediators play a facilitating role in learning and are not merely strong associations of the word pair. Recall of the response and the added word was better for the mediation group than for the association group. Also, recall of the response word given that the added word was recalled was greater in the mediation than in the association group. Although recall of both the response word and the added word may somehow have been facilitated by a third factor, the results are consistent with the idea that recall of the added word facilitated recall of the response word in the mediation group.

The results also indicate that the mediation instructions had a significantly greater effect on the concrete than on the abstract word pairs. Because concrete words are more meaningful than are abstract words (Paivio et al., 1968), it may have been easier to find a mediator for the concrete pairs. But, also, since the proportion, $\mathrm{P}(\mathrm{R}$ Ino $\mathrm{A})$, was greater for the concrete than for the abstract pairs in both groups, there may have been some visual imagery mediation taking place.

The results of this experiment support the hypothesis that the one-word mediators were not merely strong associates to the word pairs. But, if the mediator is not merely a strong associate, then the question may be raised as to what the mediator is and how it does originate. As discussed above, it may be that the mediator is a word that is a weak associate to one of the words in the pair and takes time to be generated. Once the word is generated, it is recognized by the subject as a solution to the original problem of remembering that word A goes with word B. The problem is then transformed into the simpler one of remembering that word A goes with the mediator word, which in turn goes also with word B. Because of this locating of preexisting information in memory relating words $\mathrm{A}$ and $\mathrm{B}$ to the mediator word, the two new connections are easier to remember than the original connection between words A and B. This way of looking at the natural mediation hypothesis was discussed by Bellezza and Poplawsky (1974). The learning process that takes place in the association group can be considered as the same process that takes place in the mediation group, except that the words given in the association group are not effective solutions to the learning problem.

\section{REFERENCES}

Adams, J. A., \& McIntyre, J. S. Natural language mediation and all-or-none learning. Canadian Journal of Psychology, 1967. 21, 436-449.

Bellezza. F. S.. \& Poplawsky, A. J. The function of one-word mediators in the recall of word pairs. Memory \& Cognition. 1974, 2. 447-452.

BUgELSKI, B. R. Presentation time, total time, and medication in paired-associate learning. Journal of Experimental Psychology. 1962, 63, 409-412.

Cicchetri. D. V. Extension of multiple-range tests of interaction tables in the analysis of variance: A rapid approximate solution. Psychological Bulletin, 1972, 77, 405-408.

Craik, F. I. M., \& LockhaRT, R. S. Levels of processing: A framework for memory research. Journal of Verbal Learning and Verbal Behavior, 1972, 11, 671-684.

CRAIK, F. I. M., \& Tulving, E. Depth of processing and the retention of words in episodic memory. Journal of Experimental Psychology: General, 1975, 1. 268-294.

Montague, W. E. Elaborative strategies in verbal learning and memory. In G. H. Bower (Ed.). The psychology of learning and motivation: Advances in research and theory (Vol. 6). New York: Academic Press, 1972.

Montague, W. E., Adams, J. A.. \& Kiess, H. O. Forgetting and natural language mediation. Journal of Experimental Psychology, 1966, 72. 829-833.

Paivio, A., Yuille, J. C., \& Madigan, S. A. Concreteness, imagery, and meaningfulness values for 925 nouns. Journal of Experimental Psychology Monograph Supplement, 1968, 76(1. Part 2).

REED, H. B. Associative aids: I. Their relation to learning, retention and other associations. Psychological Review, 1918, 25. 128-155.

UNDERWOOD, B. J. Are we overloading memory? In A. W. Melton \& E. Martin (Eds.), Coding processes in human memory. Washington, D.C: Winston, 1972.

UNDERWOOD, B. J., \& SChulz, R. W. Meaningfulness and verbal learning. Chicago: Lippincott, 1960.

(Received for publication August 12, 1977.) 